\section{A new combination of multiple autoimmune syndrome? Coexistence of vitiligo, autoimmune thyroid disease and ulcerative colitis}

\author{
Firdevs Topal, ${ }^{1}$ Engin Senel, ${ }^{2}$ Sabiye Akbulut, ${ }^{3}$ \\ Fatih Topal, ${ }^{4}$ Yasemin Dölek ${ }^{5}$ \\ ${ }^{1}$ Clinics of Gastroenterelogy; \\ ${ }^{2}$ Dermatology, Çankiri State Hospital, \\ Çankiri; \\ ${ }^{3}$ Department of Gastroenterology, \\ Kartal Kosuyolu High Specialty Education \\ and Research Hospital, Istanbul; \\ ${ }^{4}$ Clinics of Emergency Medicine; \\ ${ }^{5}$ Pathology, Çankiri State Hospital, \\ Çankiri, Turkey
}

\begin{abstract}
The occurrence of three or more autoimmune disorders in one patient defines multiple autoimmune syndrome. The pathogenesis of multiple autoimmune syndrome is not known yet and environmental triggers and genetic susceptibility have been suggested to be involved. Herein, we report a 47-year-old woman who had Hashimoto's thyroiditis, vitiligo and newly diagnosed ulcerative colitis. Diagnosis of ulcerative colitis was confirmed with histopathologic examination. This case presents a new combination of multiple autoimmune syndrome.
\end{abstract}

\section{Introduction}

A multiple autoimmune syndrome (MAS) consists of three or more well-defined autoimmune conditions in the same patient. It was first proposed by Humbert in 1988 and described with increasing frequency. ${ }^{1}$ Although exact pathogenesis of the syndrome is obscure, environmental triggers and genetic susceptibility may be involved. ${ }^{2}$

\section{Case Report}

A 47-year-old woman who had Hashimoto's thyroiditis for 26 years and vitiligo for 37 years presented to gastroenterology service of our hospital with bloody diarrhea for three months. Dermatological examination showed multiple depigmented macules and patches on her trunk and extremities (Figure 1). Colonoscopy revealed a hemorrhagic edematous mucosa of the colon. Histopathological examination disclosed superficial ulceration and numerous crypt abscesses, and mixed leukocytic infiltrates in lamina propria (Figure 2). A diagnosis of rectosigmoid ulcerative colitis was established by colonoscopy and histopathological examination.

\section{Discussion}

Autoimmune disorders are conditions in which there is the development of antibodies against self-cells. Multiple autoimmune syndrome is defined as a combination of at least three autoimmune diseases in the same patient. MAS can be classified into three subtypes in which certain disorders frequently occur together (Table 1), ${ }^{2,3}$ HLA-B8, -DR3 or -DR5 have been suggested to be an important factor for subtype 3 . Acquired primary hypogonadism, hypophysitis, romatoid arthritis, relapsing polychondritis, multiple sclerosis, $\mathrm{CAH}$, ulcerative colitis, and scleroderma have been reported to be associated with MAS subtype $3 .^{1,2}$

The pathogenesis of MAS is not clear yet. Environmental triggers and genetic susceptibility have been proposed to be involved., ${ }^{2,45}$ Autoimmunity has been proposed to be a prominent

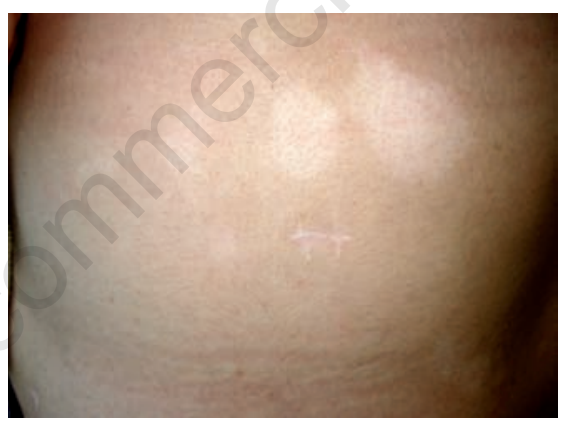

Figure 1. Depigmented patches on the back.
Correspondence: Engin Senel, Çankiri State Hospital, Clinic of Dermatology, Aksu Mah. Ogretmenler Sokak, 18200 Çankiri, Turkey.

Tel. +90.376.2131098.

E-mail: enginsenel@enginsenel.com

Key words: multiple autoimmune syndrome, autoimmunity, vitiligo, ulcerative colitis, autoimmune thyroiditis.

Received for publication: 15 July 2011. Accepted for publication: 15 July 2011.

This work is licensed under a Creative Commons Attribution NonCommercial 3.0 License (CC BYNC 3.0).

(C) Copyright F. Topal et al., 2011

Licensee PAGEPress, Italy

Dermatology Reports 2011; 3:e19

doi:10.4081/dr.2011.e19

factor for inflammatory bowel diseases. ${ }^{6}$ Snook et al. found that at least one autoimmune disorder was present in $7 \%$ of the patients with ulcerative colitis and $2 \%$ of the controls. ${ }^{7}$

Our patient had autoimmune thyroid disease, vitiligo and ulcerative colitis. Although this combination of autoimmune disorders has

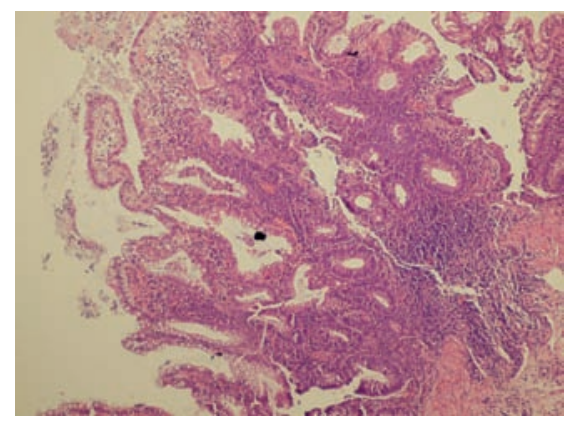

Figure 2. Crypt abscesses and mixed leukocytic infiltrates in lamina propria $(\mathrm{H} \& \mathrm{E}, \mathbf{x 1 0})$.

Table 1. Classification of multiple autoimmune syndrome.

\begin{tabular}{lll} 
MAS Type 1 & MAS Type 2 & MAS Type 3 \\
Thymoma & Rheumatoid arthritis & Autoimmune thyroid disease \\
Myasthenia gravis & Sjögren's syndrome & Myasthenia \\
\hline Polymyositis & Pemphigus vulgaris & Thymoma \\
Giant cell myocarditis & Primary biliary cirrhosis & Sjögren's syndrome, pernicious anemia \\
\hline Pemphigus vulgaris & Scleroderma & Idiopathic thrombocytopenic purpura \\
Bullous pemphigoid & Autoimmune thyroid disease & Addison's disease \\
\hline & & Insulin-dependent diabetes \\
& & Vitiligo \\
\hline & Autoimmune \\
& & Hemolytic anemia \\
\hline & Systemic lupus erythematosus \\
& & Dermatitis herpetiformis \\
\hline
\end{tabular}


not been reported before this case presents a new association that meets the requirements for the diagnosis of MAS. We suggest that this combination should be included in MAS subtype 3 .

\section{References}

1. Humbert P, Dupond JL. [Multiple autoimmune syndromes]. Ann Med Interne (Paris) 1988;39:159-68.

2. Mohan MP, Ramesh TC. Multiple autoim- mune syndrome. Indian $\mathrm{J}$ Dermatol Venereol Leprol 2003;69:298-9.

3. Tirado-Sanchez A, Montes-de-Oca G. Coexistence of bullous pemphigoid, vitiligo, and thyroid disease: a multiple autoimmune syndrome? Dermatol Online J 2005;11:20.

4. Humbert P, Dupond JL, Vuitton D, Agache P. Dermatological autoimmune diseases and the multiple autoimmune syndromes. Acta Derm Venereol Suppl (Stockh) 1989; 148:1-8.

5. Pasic A, Ljubojevic S, Lipozencic J, et al.
Coexistence of psoriasis vulgaris, bullous pemphigoid and vitiligo: a case report. J Eur Acad Dermatol Venereol 2002;16:426-7.

6. Thompson DM, Robinson TW, LennardJones J. Alopecia areata, vitiligo, scleroderma and ulcerative colitis. Proc R Soc Med 1974;67:1010-2.

7. Snook JA, de Silva HJ, Jewell DP. The association of autoimmune disorders with inflammatory bowel disease. Q J Med 1989; 72:835-40. 